\title{
LiCl Photodissociation on Graphene: A Photochemical Approach to Lithium Intercalation
}

\author{
Jon Azpeitia, Pablo Merino, Sandra Ruiz-Gómez, Michael Foerster, Lucía Aballe, Mar García-Hernández, \\ José Ángel Martín-Gago, and Irene Palacio*
}

Cite This: ACS Appl. Mater. Interfaces 2021, 13, 42205-42211

Read Online

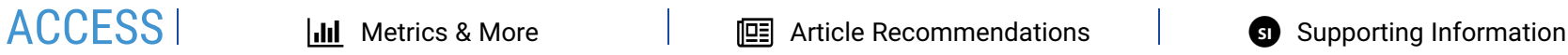

ABSTRACT: The interest in the research of the structural and electronic properties between graphene and lithium has bloomed since it has been proven that the use of graphene as an anode material in lithium-ion batteries ameliorates their performance and stability. Here, we investigate an alternative route to intercalate lithium underneath epitaxially grown graphene on iridium by means of photon irradiation. We grow thin films of $\mathrm{LiCl}$ on top of graphene on $\operatorname{Ir}(111)$ and irradiate the system with soft X-ray photons, which leads to a cascade of physicochemical reactions. Upon $\mathrm{LiCl}$ photodissociation, we find fast chlorine desorption and a complex sequence of lithium intercalation processes. First, it intercalates, forming a disordered structure between graphene and iridium. On increasing the irradiation time, an ordered $\mathrm{Li}(1 \times 1)$ surface structure forms, which evolves upon extensive photon

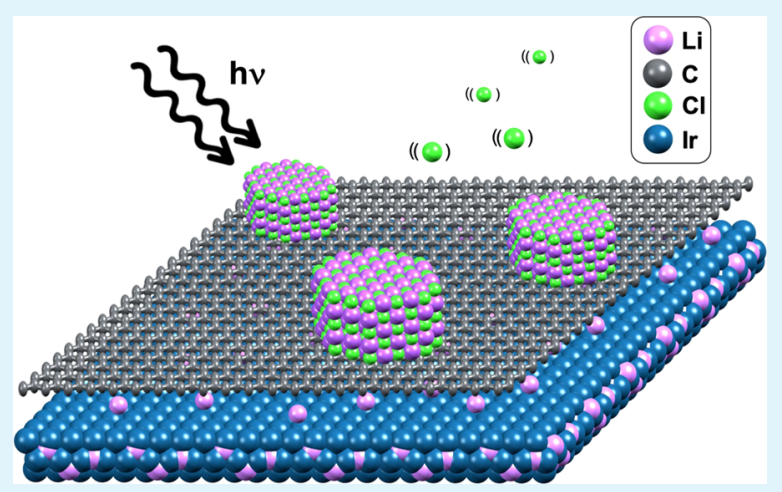
irradiation. For sufficiently long exposure times, lithium diffusion within the metal substrate is observed. Thermal annealing allows for efficient lithium desorption and full recovery of the pristine $\mathrm{G} / \operatorname{Ir}(111)$ system. We follow in detail the photochemical processes using a multitechnique approach, which allows us to correlate the structural, chemical, and electronic properties for every step of the intercalation process of lithium underneath graphene.

KEYWORDS: lithium, graphene, intercalation, photodissociation, lithium-ion chemistry

\section{INTRODUCTION}

Graphene (Gr) has been extensively studied over the past decade, ${ }^{1}$ and there is a significant amount of works regarding the intercalation of small molecules or atoms in graphitic-like nanostructures. ${ }^{2-4}$ In particular, the intercalation of alkali metals under epitaxial graphene has been widely studied ${ }^{5-7}$ since it is a possible route to tailor the graphene band structure and doping level. Among alkali metals, lithium is especially interesting since, in addition to its capability to engineer graphene doping, ${ }^{8-10}$ it bears direct technological applications for graphene-based lithium-ion batteries. ${ }^{11-14}$ In that context, several strategies have appeared focusing on obtaining lithium-intercalated graphene as an anode material by chemical methodologies. ${ }^{11}$ Nanomaterials, and particularly crystalline carbon materials, such as graphite or graphene, play a critical role since they present high mechanical flexibility (volume expansion) and higher electrical conductivity (good electrical contact for several cycles $)^{15-17}$ and enhance the reaction/protection of the active material in batteries. ${ }^{18}$ Moreover, the core processes happening in a lithium-ion battery (charge and discharge) are based on the rocking-chair ${ }^{19}$ or intercalation chemistry. Therefore, alternative routes allowing the intercalation of lithium underneath graphene as well as a detailed description at the atomic level of the structures formed during the intercalation processes may be of interest in the field.

In this work, we present a combined synchrotron-based X-ray photoemission electron microscopy/low-energy electron microscopy (XPEEM/LEEM) study of the Li/Gr system. The combined use of diffracted low-energy electrons and photoelectrons allows us to follow in real time the chemical, structural, and electronic processes occurring during lithium intercalation through graphene. We show that $\mathrm{LiCl}$ thin films on top of a single layer of graphene grown on an $\operatorname{Ir}(111)$ substrate photodissociate upon exposure to soft X-ray photons. We observe rapid chlorine-ion desorption and a sequence of rapidly evolving lithium intercalation processes. In the first stage, $\mathrm{Li}$ intercalates, forming an amorphous two-dimensional (2D) structure that successfully decouples graphene from the $\operatorname{Ir}(111)$ substrate. For increasing irradiation time, Li reorganizes below graphene, forming an intercalated $(1 \times 1)$ structure. Upon

Received: June 22, 2021

Accepted: August 11, 2021

Published: August 25, 2021 


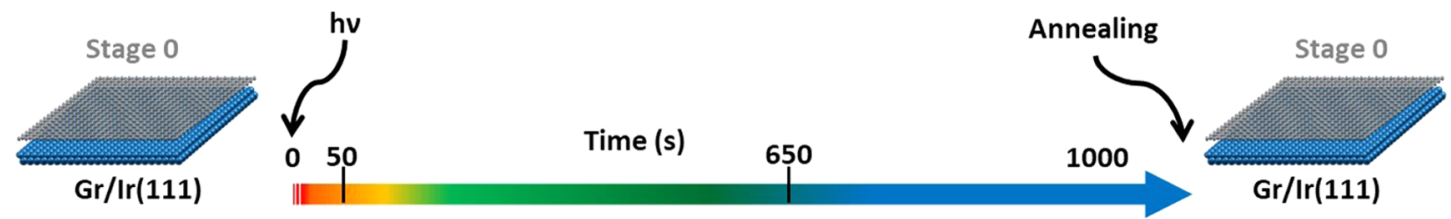

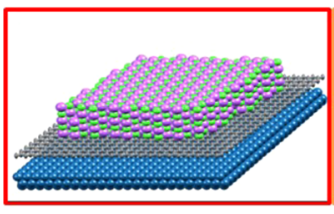

LiCl/Gr/Ir(111)

Stage 1

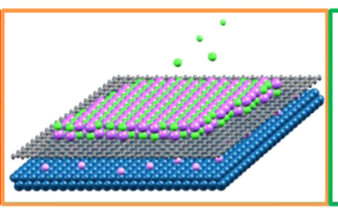

Gr/a-Li/Ir(111)

Stage 2

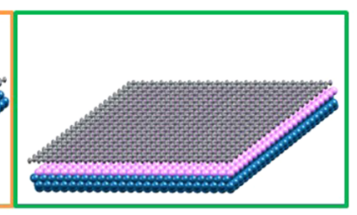

$\mathrm{Gr} / \mathrm{Li}(1 \times 1) / \operatorname{Ir}(111)$

Stage 3

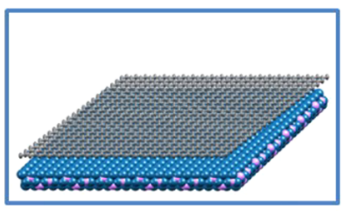

Gr/Ir-Li/Ir(111)

Stage 4

Figure 1. Scheme of the different stages involved in the Li intercalation processes through graphene by photodissociation. Stage 0 represents a pristine $\mathrm{Gr} / \mathrm{Ir}(111)$ sample. Stage 1 consists of a $\mathrm{LiCl}$ thin film grown on top of the graphene. From stage 2 to stage 4 , the sample is continuously irradiated with photons $(h \nu=136 \mathrm{eV})$. Upon irradiation, $\mathrm{LiCl}$ dissociates, $\mathrm{Cl}$ desorbs, and $\mathrm{Li}$ intercalates through graphene (stage 2 ). When a full monolayer coverage is reached, Li forms a $(1 \times 1)$ structure (stage 3). For longer exposures, Li intercalates deeper into the subsurface region of the $\operatorname{Ir}(111)$ (stage 4$)$. Upon annealing, the pristine sample is recovered undamaged (stage 0 ). The different stages are color coded according to the timeline: stage 1, red; stage 2, orange; stage 3, green; and stage 4, blue. The color of atoms in the scheme is such that purple, green, gray, and blue represent $\mathrm{Li}$, $\mathrm{Cl}, \mathrm{C}$, and $\mathrm{Ir}$, respectively.

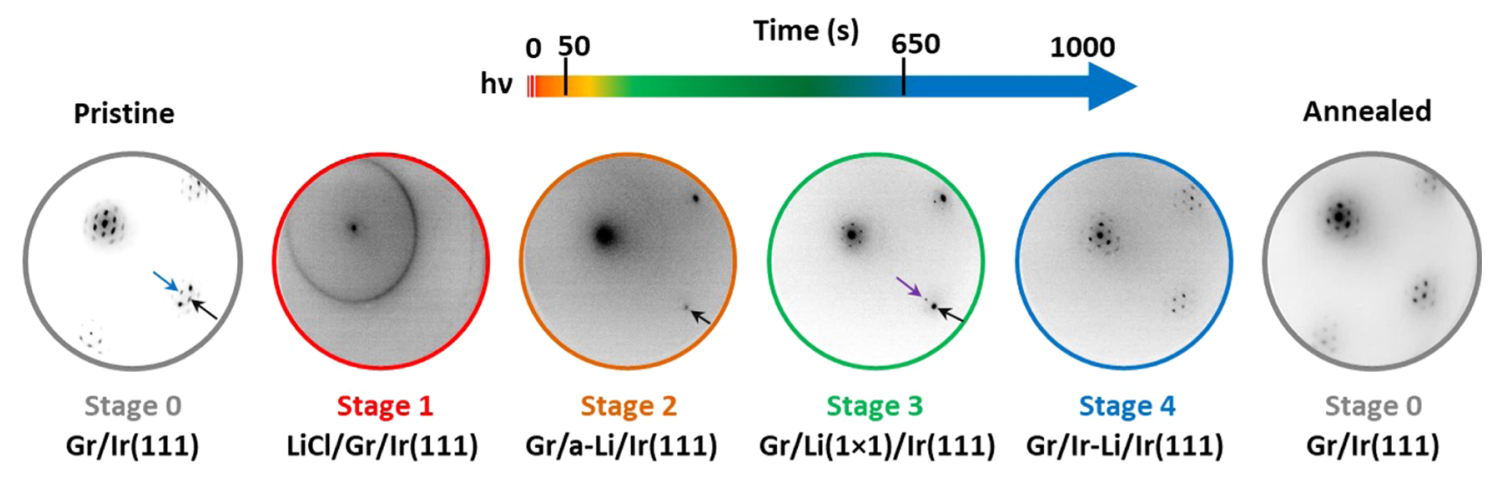

Figure 2. Structural evolution over time and key stages, numbered $0-4$, of the irradiated system. Low-energy electron diffraction (LEED) patterns during the photodissociation process $(h \nu=136 \mathrm{eV})$ and posterior interaction of $\mathrm{Li}$ of the $\mathrm{LiCl} / \mathrm{Gr} / \mathrm{Ir}(111)$ system are presented, and the characteristic irradiation times are represented in the upper arrow. All patterns were acquired with an electron energy of $65 \mathrm{eV}$. Time $0 \mathrm{~s}$ represents the beginning of the irradiation. Black, blue, and purple arrows indicate $\mathrm{Gr}$ spots, Ir spots, and $\mathrm{Li}(1 \times 1)$ spots, respectively.

further extensive irradiation, lithium diffuses into subsurface positions in the metal.

\section{EXPERIMENTAL METHODS}

All of the experiments have been carried out in the LEEM/PEEM experimental end station of the CIRCE beamline at the ALBA Synchrotron. ${ }^{20}$ Since the sample surface is homogeneous, we generally used the largest available aperture size of $10 \mu \mathrm{m}$ diameter for microspot measurements, having only occasionally employed the $5 \mu \mathrm{m}$ diameter one. For repeated or different measurements, the sample was moved to obtain a fresh area for each exposure cycle. Samples were prepared in an ultrahigh vacuum (UHV) chamber with a base pressure of $1 \times 10^{-10}$ mbar. $\mathrm{LiCl}$ ( $\geq 99.98 \%$, Sigma-Aldrich) was sublimated from a homemade Ta crucible annealed at $720 \mathrm{~K}$ controlled by a type- $\mathrm{K}$ thermocouple spot-welded to it with the sample kept at room temperature. $\operatorname{Ir}(111)$ surfaces were cleaned by repeated cycles of argon-ion sputtering and annealing in an oxygen atmosphere $(T=1373$ $\mathrm{K}$ and $\left.P_{\text {oxygen }}=2 \times 10^{-8} \mathrm{mbar}\right)$. To avoid any residual oxygen on the surface, the last cleaning cycle was carried out without oxygen. Graphene was grown on a single crystal of $\operatorname{Ir}(111)$, crystallographic plane (111), in a decomposition process of ethylene. In the first step, ethylene $\left(P=1 \times 10^{-8} \mathrm{mbar}\right.$ during $\left.30 \mathrm{~s}\right)$ is adsorbed on the sample at room temperature (RT), and then the sample is flashed up to $1373 \mathrm{~K}$ for $30 \mathrm{~s}$. In the second step, the sample is exposed to a higher ethylene pressure $\left(P=1 \times 10^{-7} \mathrm{mbar}\right)$, again followed by thermal decomposition at $1373 \mathrm{~K}$ for $7 \mathrm{~min}^{21}$

\section{RESULTS AND DISCUSSION}

Figure 1 presents a scheme of the different stages of our experiments. As a starting point, we have a pristine $\mathrm{Gr} / \operatorname{Ir}(111)$ sample (stage 0 ). Stage 1 consists of a thin $\mathrm{LiCl}$ film (typically 5-7 monolayers thick) grown on top of graphene: $\mathrm{LiCl} / \mathrm{Gr}$ / $\operatorname{Ir}(111)$. The exposition of this system to photon irradiation $(h \nu$ $=136 \mathrm{eV}$, photon flux about $2.5 \times 10^{9}$ photons $\left./ \mathrm{s} \cdot \mu \mathrm{m}^{2}\right)$ activates the $\mathrm{Li}$ photochemistry and triggers the subsequent $\mathrm{Li}$ intercalation stages. Immediately after starting the irradiation, the $\mathrm{LiCl}$ layers start to photodissociate. During this photoinduced reaction, $\mathrm{LiCl}$ dissociates, lithium reduces and intercalates, and chlorine oxidizes, presumably desorbing as $\mathrm{Cl}_{2}$, although we cannot rule out the possibility of chlorine-ion desorption without recombination. This leads to stage 2 , which is obtained during the first $10-20 \mathrm{~s}$ of photon exposure and consists of an amorphous Li layer intercalated between graphene and $\operatorname{Ir}(111): \mathrm{Gr} / \mathrm{a}-\mathrm{Li} / \mathrm{Ir}(111)$. Because $\mathrm{LiCl}$ films are several monolayers thick, there is a gradual process of continuous intercalation that lasts for the first $100 \mathrm{~s}$. When the coverage of intercalated $\mathrm{Li}$ reaches the monolayer $(\mathrm{ML})$, lithium orders in a $\mathrm{Li}(1 \times 1)$ superstructure, resulting in stage $3: \mathrm{Gr} / \mathrm{Li}(1 \times 1) /$ $\operatorname{Ir}(111)$. After long irradiation times, $500-600 \mathrm{~s}$, the $\mathrm{LiCl}$ thin film is completely photodissociated, and the next stage of evolution is reached. In stage $4, \mathrm{Li}$ atoms penetrate into $\operatorname{Ir}(111)$ 
(a)

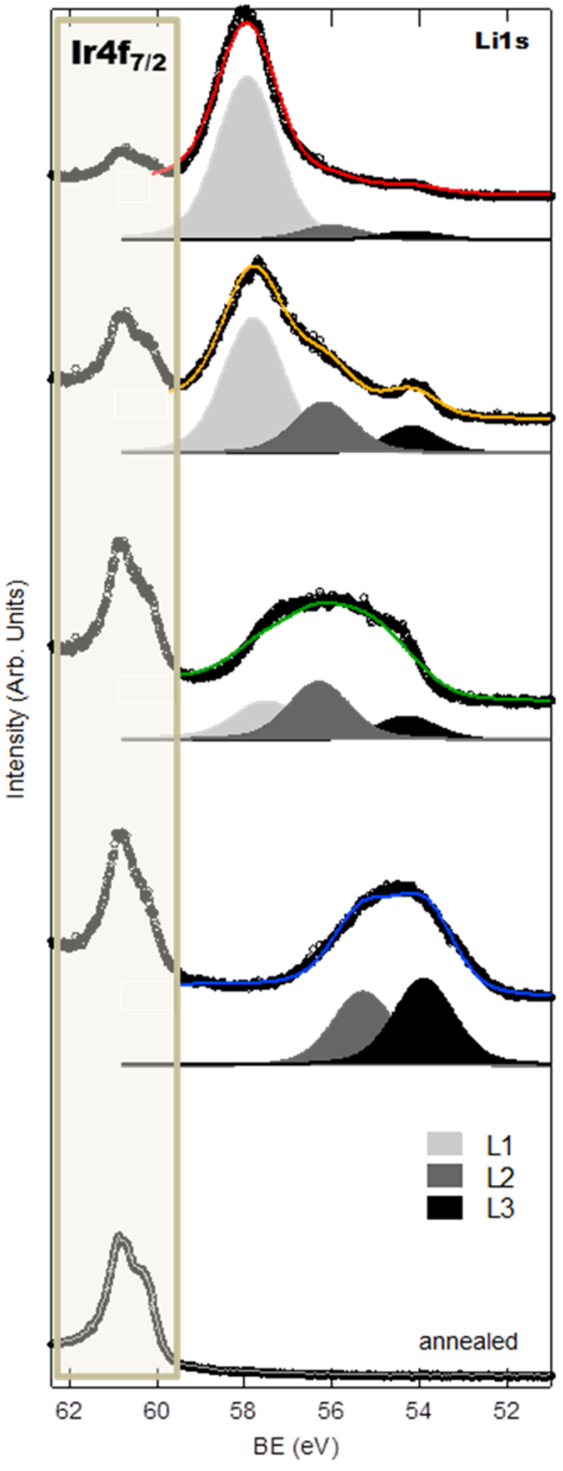

(b)

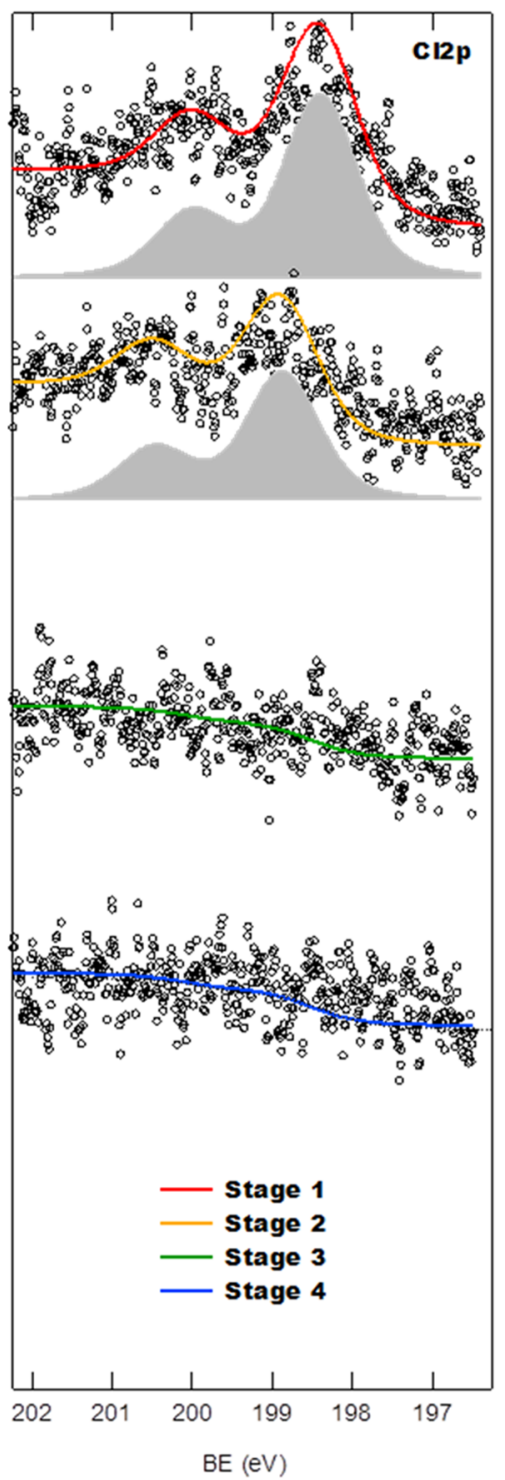

(c)

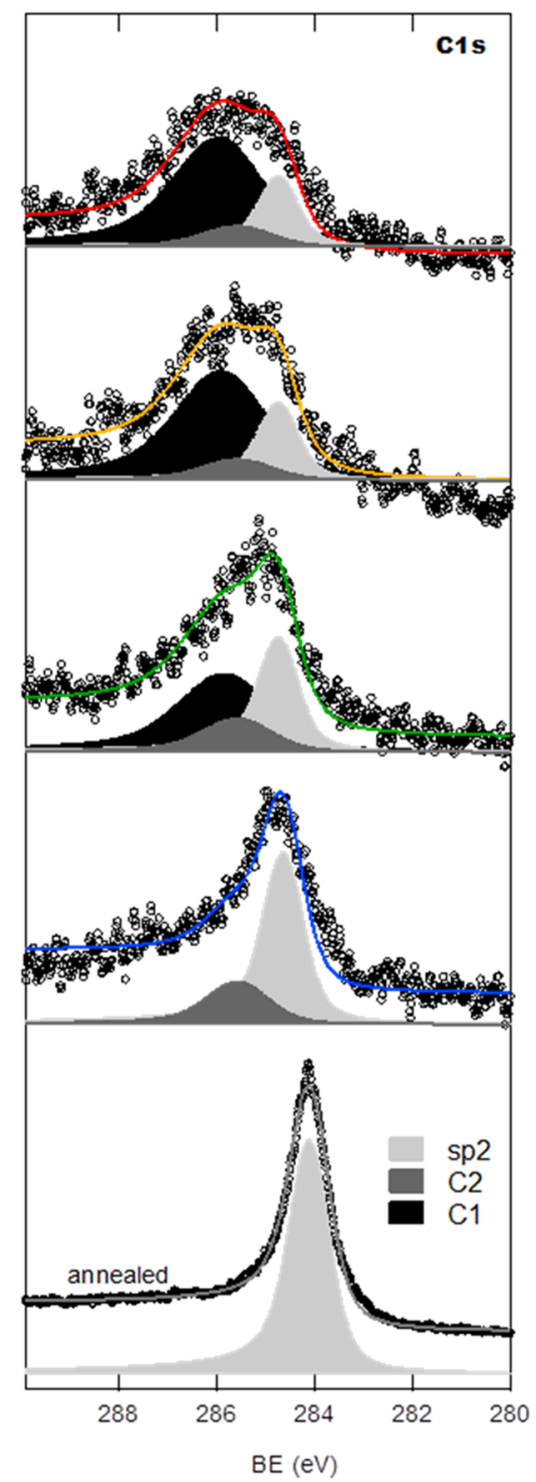

Figure 3. (a) Evolution of the $\mathrm{Li} 1$ s core-level spectra and its components of the $\mathrm{LiCl} / \mathrm{Gr} / \mathrm{Ir}(111)$ system upon exposure to photons of $136 \mathrm{eV}$ (red, yellow, blue, and green spectra) and after annealing at $900{ }^{\circ} \mathrm{C}$ (gray spectrum). (b, c) Evolution of the $\mathrm{Cl} 2 \mathrm{p}$ and $\mathrm{C}$ 1s core levels and their components upon irradiation at $h \nu=400 \mathrm{eV}$, respectively.

first few layers and adopt subsurface positions: $\mathrm{Gr} / \mathrm{Ir}-\mathrm{Li} /$ $\operatorname{Ir}(111)$. Stage 4 is the final stable stage observed in our experimental sessions for sufficiently long photon exposure times. It is therefore presumably the most energetically favorable configuration while irradiating. In addition, we note that the pristine $\mathrm{G} / \operatorname{Ir}(111$ ) (stage 0 ) can be recovered from stage 4 by annealing the sample up to $900{ }^{\circ} \mathrm{C}$.

The full sequence of processes has been studied in real time by a multitechnique in situ characterization in the PEEM/LEEM experimental station at the Alba Synchrotron. ${ }^{20}$ The structure evolution was followed by low-energy electron diffraction (LEED), the chemical evolution was tracked by X-ray photoemission spectroscopy (XPS), and the band structure was measured with microspot angle-resolved photoemission spectroscopy ( $\mu$-ARPES). Although we have used an ideal substrate to depict the process, the results can be extrapolated to other $\mathrm{sp}^{2}$-based materials, like graphite, graphene on $\mathrm{SiC}$, or free- standing graphene flakes, and more likely to any other $2 \mathrm{D}$ van der Waals system.

3.1. Structural Evolution. Figure 2 presents the structural evolution of the system as followed by microspot LEED (see also Supporting Information Movie 1). All of the diffraction patterns were measured at the same electron energy $(65 \mathrm{eV})$ in real time on the same sample, allowing a direct comparison between the different irradiation stages. The largest illumination aperture (10 $\mu \mathrm{m}$ diameter) was used in all cases. Control experiments show that the low-energy electrons of the LEED alone have a negligible effect on the chemistry of $\mathrm{LiCl}$ films.

The diffraction pattern of stage 0 is a flower-pattern structure arising from the moire pattern observed on the pristine $\mathrm{Gr}$ / $\operatorname{Ir}(111)$ (Figure 2 gray circle). ${ }^{22}$ In this pattern, iridium (blue arrow), graphene (black arrows), and the moire spots are well resolved. In stage 1 , a thin film of $\mathrm{LiCl}$ is grown on the sample at room temperature; as a result, a new feature appears in the LEED pattern in the form of a ring (Figure 2 circled in red). The 
intensity distribution from $(0,0)$ is consistent with the $\mathrm{LiCl}$ lattice parameter, and the appearance of a ring-like feature demonstrates that multiple rotational domains of the $\mathrm{LiCl}$ crystallites coexist physisorbed on the graphene layer. Because there are no graphene and/or iridium spots, we can estimate the minimal thickness of the $\mathrm{LiCl}$ films to be between five and seven monolayers.

At time $(t)$ zero, we start photon irradiation at $16^{\circ}$ grazing incidence on the $\mathrm{LiCl} / \mathrm{Gr} / \mathrm{Ir}(111)$ sample. In the first $10-20 \mathrm{~s}$, a dramatic change is observed in the diffraction pattern (Figure 2 circled in orange), corresponding to the appearance of stage 2 . At this stage, $\mathrm{LiCl}$ starts to photodissociate and, while chlorine desorbs (see XPS results below), lithium atoms begin to intercalate through graphene, most probably via structural defects. ${ }^{23}$ In the LEED pattern, we identify this process as a rapid fainting of the LiCl-related ring and appearance of intense graphene spots (black arrows). Indeed, we observed a similar effect during intercalation of $\mathrm{NaCl}^{22}$ Comparison of the evolution with and without $\mathrm{X}$-ray irradiation demonstrates that the primary cause for $\mathrm{LiCl}$ dissociation and thus $\mathrm{Li}$ intercalation is the illumination from the synchrotron, although we cannot fully rule out a small effect of the electron gun used for LEED, probably in the form of desorption of a small fraction of $\mathrm{LiCl}$. The detection of an intense graphene diffraction pattern and the absence of any moiré spots are clear signs of intercalation-induced decoupling. ${ }^{24}$ It has been reported that submonolayer lithium intercalation can efficiently decouple graphene from the metal substrate, ironing out its corrugation. ${ }^{25}$ At stage 2, neither the $\operatorname{Ir}(1 \times 1)$ spots nor any other Li-related features are resolved, pointing out the lack of crystallinity in the Li-intercalated layer. ${ }^{9}$

After the first $20 \mathrm{~s}$, stage 2 quickly evolves into stage 3, where the appearance of the $\operatorname{Ir}(111)(1 \times 1)$ spots (purple arrow) in the diffraction pattern (Figure 2 circled in green) indicates the formation of a $\operatorname{Li}(1 \times 1)$ superstructure. The $\operatorname{Li}(1 \times 1) / \operatorname{Ir}(111)$ reconstruction after full ML coverage has been reported by Pervan et al. ${ }^{9}$ When $\operatorname{Gr} / \operatorname{Li}(1 \times 1) / \operatorname{Ir}(111)$ is reached, the graphene layer remains structurally decoupled from the metal surface and there are no moire spots in the diffraction pattern. In our experimental sessions, stage 3 lasts over $600 \mathrm{~s}$ of photon irradiation time. During this long irradiation time, the background intensity around the $(0,0)$ spot gradually increases and finally the moire LEED spots start to become visible. A sudden change at around $700 \mathrm{~s}$ leads to stage 4 (Figure 2 circled in blue). At this point, as will be shown below, $\mathrm{Li}$ stays intercalated under graphene but in addition diffuses into subsurface positions of the iridium substrate. This results in large portions of the metal surface being clean of $\mathrm{Li}$ atoms, thus forming a regular layer of $\operatorname{Ir}(111)$ just below graphene and hence allowing graphene to couple to Ir, form the moire structure, and recover the intrinsic $\mathrm{Gr} / \mathrm{Ir}(111)$ corrugation. This is demonstrated by the reappearance of the moire spots ( $\mathrm{Gr} / \mathrm{Ir}-\mathrm{Li}$ / $\operatorname{Ir}(111))$. Finally, the photon flux is turned off and the sample is annealed up to $900{ }^{\circ} \mathrm{C}$, which leads to a recovered pristine $\mathrm{Gr} /$ $\operatorname{Ir}(111)$ sample, i.e., stage 0 . A full video of the process tracked by LEED is shown in Supporting Information Movie 1.

3.2. Chemical Evolution. In the following, we analyze the chemical evolution of the system by tracking the main core levels involved in the process. The $\mathrm{Li} 1 \mathrm{~s}, \mathrm{Cl} 2 \mathrm{p}$, and $\mathrm{C} 1 \mathrm{~s}$ XPS peaks were measured using photon energies of $136 \mathrm{eV}$ (Li core-level) and $400 \mathrm{eV}$ ( $\mathrm{Cl} \mathrm{2p}$ and $\mathrm{C} 1 \mathrm{~s}$ core levels), respectively. The photon energy used to measure $\mathrm{C} 1 \mathrm{~s}$ and $\mathrm{Cl} 2 \mathrm{p}$ is not the same as the one used for the lithium core-level and for the LEED studies presented above. Control experiments show similar evolution dynamics for both energies, suggesting that the photophysically induced processes are analogous in the X-ray energy range inspected here. Figure 3 summarizes the evolution with exposure time and after annealing at $900{ }^{\circ} \mathrm{C}$ of $\mathrm{Li} 1 \mathrm{~s}$ (Figure $3 a), C l 2 p$ (Figure $3 b$ ), and C 1s (Figure 3c) core-level spectra.

$\mathrm{Li} 1 \mathrm{~s}$ and $\mathrm{Ir} 4 \mathrm{f}_{7 / 2}$ spectra are shown in Figure $3 \mathrm{a}$ (see also Figure $\mathrm{S} 1$ ). The $\mathrm{Ir} 4 \mathrm{f}_{7 / 2}$ core-level appears at a binding energy (BE) of $60.8 \mathrm{eV} .^{26}$ We resolve three different components for the $\mathrm{Li} 1 \mathrm{~s}$ (Figure 3a): L1 (at $57.9 \mathrm{eV}$ ) is the main component in stage 1 and dramatically decreases upon beam exposure, almost disappearing in stage 3 . This component can be assigned to the $\mathrm{Li}$ atoms in a $\mathrm{LiCl}$ crystal in good agreement with the LEED results (Figure 2). The behavior of $\mathrm{L} 1$ matches with the $\mathrm{Cl} 2 \mathrm{p}$ core-level evolution as will be shown below. As L1 starts to decrease, two new peaks at lower BEs emerge, L2 and L3 at 56.1 and $54.3 \mathrm{eV}$, respectively. We assign $\mathrm{L} 2$ to the intercalated lithium sandwiched between the graphene and the iridium surface (stage 2: Gr/a-Li/Ir(111)). ${ }^{27}$ The L2 component intensity increases and shifts toward a lower BE (up to 55.2 $\mathrm{eV})$ as the Li-intercalated coverage increases up to the monolayer saturation coverage and the system reaches stage 3 $(\mathrm{Gr} / \mathrm{Li}(1 \times 1) / \operatorname{Ir}(111)){ }^{8}$ The $\mathrm{L} 3$ component also appears in the first stage but dramatically increases in stage 4 . We assign this component to $\mathrm{Li}$ atoms intercalated below the first iridium layers. At the end of stage $3, \mathrm{LiCl}$ has completely disappeared and the intercalated $\mathrm{Li}$ coverage saturates but irradiation continues. As a consequence, $\mathrm{Li}$ atoms are forced to intercalate in subsurface positions, and the system would eventually reach stage $4, \mathrm{Gr} / \mathrm{Ir}-\mathrm{Li} / \mathrm{Ir}(111){ }^{25}$ The presence of the $\mathrm{L} 3$ component demonstrates that lithium is present in the sample even though the LEED pattern resembles that of a clean $\mathrm{Gr} / \mathrm{Ir}(111)$ system. Only after the high-temperature annealing (gray spectrum), all Li 1s components disappear and the structure, chemistry, and energy bands of pristine $\mathrm{Gr} / \mathrm{Ir}(111)$ are recovered.

If we now turn to the $\mathrm{Cl} 2 \mathrm{p}$ peak $^{28}$ (Figure $3 \mathrm{~b}$ ), we note a strong intensity decrease from the first seconds of irradiation as well as a small shift toward a higher BE. This is a clear indication of chlorine desorption, presumably upon evaporation as $\mathrm{Cl}_{2}$, after photodissociation. All traces of the $\mathrm{Cl} 2 \mathrm{p}$ peak disappear during stage 3 in good agreement with the behavior observed for the Li L1 component. Moreover, no other new chlorine-related components are found, indicating that no new chlorine subspecies are formed.

Finally, we focus on the $\mathrm{C} 1$ s core-level (Figure 3c). In stage 1, when the $\mathrm{LiCl}$ thin film is present on top of graphene and prior to irradiation, C $1 \mathrm{~s}$ appears as a broad peak with three components. We assign one of them $\left(\mathrm{sp}^{2}\right)$ to $\mathrm{C}$ atoms in the $\mathrm{sp}^{2}$ configuration and note a small shift $(0.7 \mathrm{eV})$ toward a higher $\mathrm{BE}$ with respect to pristine $\mathrm{Gr} / \mathrm{Ir}(284.1 \mathrm{eV}){ }^{8,25}$ which points toward an effective n-type doping of graphene. ${ }^{8}$ At this stage, there is also a broad component $(\mathrm{C} 1)$ at a higher $\mathrm{BE}$ that we assign to a combination of charge effects as a consequence of the insulating $\mathrm{LiCl}$ film and the $\mathrm{LiCl} / \mathrm{Gr}$ interface (mostly $\mathrm{Li}$ atoms interacting with $\mathrm{Gr}$ ). Component $\mathrm{C} 1$ is reduced drastically upon irradiation, disappearing completely at the end of stage 3 where no traces of $\mathrm{LiCl}$ can be detected. A smaller component (C2) appearing as a shoulder at a higher $\mathrm{BE}$ of the $\mathrm{sp}^{2}$ one $(0.8 \mathrm{eV}$ w.r.t. $\left.\mathrm{sp}^{2}\right)$ remains almost unperturbed during the evolution of the system and is related to the $\mathrm{n}$-doping of graphene. Such a component has been observed in the literature for graphitic systems interacting with lithium and other alkali metals. ${ }^{8}$ After annealing (gray spectrum) and recovering stage 0 , the $C$ s peak 
shifts toward a lower $\mathrm{BE}$ and narrows, and only the $\mathrm{sp}^{2}$ component of graphene on $\operatorname{Ir}(111)$ is resolved. ${ }^{8,25}$

3.3. Band Structure Evolution. All of the structural and chemical changes introduced above will necessarily have a direct impact on the electronic band structure of the system. Using $\mu$ ARPES $(h \nu=136 \mathrm{eV})$, we track the changes in the band structure and therefore in the doping of graphene across all of the stages of evolution (see Figure S2 and Supporting Information Movie 2). Figure 4 shows the constant-energy

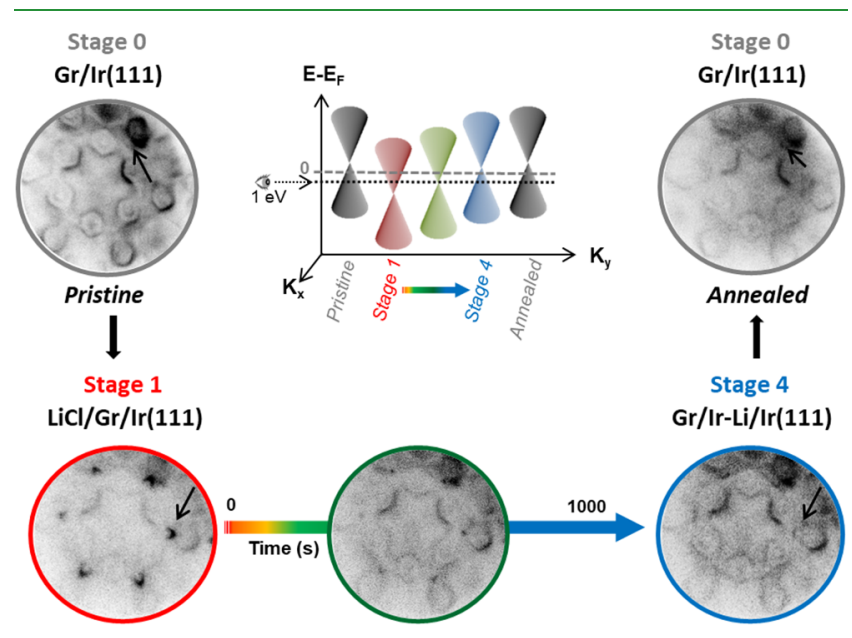

Figure 4. Constant-energy maps at $E-E_{\mathrm{F}}=1 \mathrm{eV}$ of the different stages on photon exposure $(h \nu=136 \mathrm{eV})$ from the $\mathrm{LiCl} / \mathrm{Gr} / \mathrm{Ir}(111)$ system to the posterior lithium intercalation. Stage 0 (circled gray) represents the pristine sample $\mathrm{Gr} / \operatorname{Ir}(111)$, and stages $1-4$ represent the stages upon photon exposure. The black arrows point out the changes in one of the dispersive $\pi$-bands. Central panel: scheme of the evolution of the Dirac cone through stages $0-4$, depicting the $\mathrm{p}-\mathrm{n}-\mathrm{p}$ changes in the doping of the graphene.

maps at $1 \mathrm{eV}$ below the Fermi level (FL) in stages 0-4, measured in real time under irradiation. The iridium bulk bands and the dispersive $\pi$-bands of graphene (indicated by black arrows in Figure 4) at the corners of the hexagonal Brillouin zone, which are the most affected by the photodissociation of $\mathrm{LiCl}$, are simultaneously resolved.

In stage 0 , the $\mu$-ARPES energy cuts reveal the $\mathrm{p}$-doped nature of the $\mathrm{Gr} / \mathrm{Ir}(111)$ system. ${ }^{29,30}$ The growth of a $\mathrm{LiCl}$ film on top of graphene leads to a radical displacement of the Dirac cones, resulting in an effective $n$-doping of the graphene layer (also observed in the XPS spectra, Figure 3c). We measure a displacement of about $1.6 \mathrm{eV}$ of the Dirac point of graphene with respect to stage 0 (see Supporting Information Figure S3), possibly due to electrostatic effects created by the insulating $\mathrm{LiCl}$ film (as pointed out by the $\mathrm{C} 1$ component in the $\mathrm{C} 1 \mathrm{~s}$ core-level, Figure $3 \mathrm{c}$ ). We note the absence of any measurable gap opening in good agreement with a situation where the $\mathrm{LiCl}$ layers physisorb on graphene keeping the $\mathrm{sp}^{2}$ structure intact. When the sample is irradiated, we observe a strong and fast shift of the dispersive $\pi$-bands (marked in Figure 4 by black arrows). During this process, the system evolves through stage 1 , to stage $2(\mathrm{Gr} /$ a- $\mathrm{Li} / \operatorname{Ir}(111))$, to stage $3(\mathrm{Gr} / \mathrm{Li}(1 \times 1) / \operatorname{Ir}(111))$, and ends up in stage $4(\mathrm{Gr} / \mathrm{Ir}-\mathrm{Li} / \mathrm{Ir}(111))$. The rapid evolution of the system and the long integration times needed for obtaining low-noise $\mu$ ARPES maps hinder precise measurements of the doping shift in the nonequilibrium stages (stages 2 and 3). However, comparison with the literature allows us to conclude that we obtain the expected $\mathrm{n}$-doping of a Li-intercalated graphene sample of around $1.52^{5}-1.63 \mathrm{eV} .^{9}$ In stage 4 , the Dirac cones almost recover their original pristine state. This is consistent with the situation where lithium is no longer underneath graphene but in a subsurface position. As expected, the $\mathrm{Gr}$ / $\operatorname{Ir}(111)$ bands are completely recovered after annealing.

\section{CONCLUSIONS}

In summary, we present a method to intercalate lithium at the graphene/iridium interface by photodissociation of an adsorbed $\mathrm{LiCl}$ thin film. A combined characterization with LEEM, XPS, and $\mu$-ARPES allows us to follow every step of the intercalation process in real time. We show that upon photon exposure, $\mathrm{LiCl}$ dissociates, chlorine atoms desorb, and lithium intercalates graphene. This is evidenced by the changes of the diffraction patterns, the fast decrease of $\mathrm{Cl} 2 \mathrm{p}$ core-level intensity, and the evolution of the $\mathrm{Li} 1 \mathrm{~s}$ peak. When the intercalated lithium amounts to one monolayer, a $1 \times 1$ structure appears in the LEED pattern. Finally, the process reaches a final state with lithium remaining in a subsurface position in the iridium substrate, as evidenced by the lithium core-level signal and the LEED pattern. $\mu$-ARPES measurements show a high $\mathrm{n}$-doped graphene behavior from the beginning of the $\mathrm{Li}$ intercalation processes. As the intercalation process takes over, graphene bands evolve to an effective p-doped behavior. The photoinduced sequence does not damage the graphene layer, as evidenced by the fact that the $\mathrm{Gr} / \mathrm{Ir}(111)$ original stage can be recovered upon high-temperature annealing. Our fundamental study contributes to a better understanding of the $\mathrm{Li}$ intercalation process in graphitic materials upon photophysical methods, which may lead to new pathways for the improvement of next-generation graphene-based anodes for lithium-ion batteries.

\section{ASSOCIATED CONTENT}

\section{Supporting Information}

The Supporting Information is available free of charge at https://pubs.acs.org/doi/10.1021/acsami.1c11654.

Detailed evolution of the $\mathrm{L} 1$ s core-level upon photon irradiation $(h \nu=136 \mathrm{eV})$ of a $\mathrm{LiCl}$ film grown on top of a $\mathrm{Gr} / \mathrm{Ir}(111)$ substrate; complete set of constant-energy maps at different energies on photon exposure time for the photo-induced $\mathrm{Li}$ intercalation in a $\mathrm{Gr} / \mathrm{Ir}(111)$ sample; constant-energy maps taken at different $E-E_{\mathrm{F}}$ energies $(h \nu=136 \mathrm{eV})$ from 0.25 up to $2.6 \mathrm{eV}$ below the Fermi level for stage 1 of the $\mathrm{LiCl} / \mathrm{Gr} / \mathrm{Ir}(111)$ system (PDF); $50 \mu \mathrm{m}$ field of view Low Energy Electron Microscopy (LEEM) image of a $\mathrm{LiCl} / \mathrm{Gr} / \mathrm{Ir}(111)$ sample; and estimation of the $\mathrm{LiCl}$ photodissociation efficiency.

In situ microspot LEED video at $65 \mathrm{eV}$ while the $\mathrm{LiCl} /$ $\mathrm{Gr} / \mathrm{Ir}(111)$ sample is irradiated with photons at $136 \mathrm{eV}$. The changes that can be appreciated during the video show how the surface structure of the system evolves upon irradiation. The starting diffraction pattern is the one of a $\mathrm{LiCl}$ film grown on top of a $\mathrm{Gr} / \mathrm{Ir}(111)$ sample. The irradiation starts the moment the first changes are observed in the diffraction pattern. The video reveals the fast transformation leading to the photodissociation of $\mathrm{LiCl}$ to the posterior intercalation of $\mathrm{Li}$ from a structural point of view (Movie 1) (AVI)

In situ $\mu$-ARPES video showing the evolution of the iridium bulk bands and the dispersive $\pi$-bands during 
photon exposure at $136 \mathrm{eV}$. The video shows a constantenergy map at $E-E_{\mathrm{f}}=0.85 \mathrm{eV}$ and its evolution during photon irradiation of a $\mathrm{LiCl} / \mathrm{Gr} / \mathrm{Ir}(111)$ sample. As changes occur very fast, to be able to track them, we first start in an already exposed region of the sample, and then we move into a "fresh" zone. The $\mu$-ARPES video reveals the shift of the dispersive $\pi$-bands, from a heavily n-doped to a slightly p-doped graphene when the photoinduced process is finished and the remaining lithium settles in a subsurface position in the iridium (Movie 2) (AVI)

\section{AUTHOR INFORMATION}

\section{Corresponding Author}

Irene Palacio - Materials Science Factory, Dept. Surfaces, Coatings and Molecular Astrophysics, Institute of Material Science of Madrid (ICMM-CSIC), 28049 Madrid, Spain; (ㄱ orcid.org/0000-0002-3345-4848; Email: i.palacio@ csic.es

\section{Authors}

Jon Azpeitia - Materials Science Factory, Dept. Surfaces, Coatings and Molecular Astrophysics, Institute of Material Science of Madrid (ICMM-CSIC), 28049 Madrid, Spain

Pablo Merino - Materials Science Factory, Dept. Surfaces, Coatings and Molecular Astrophysics, Institute of Material Science of Madrid (ICMM-CSIC), 28049 Madrid, Spain; Instituto de Física Fundamental, E28006 Madrid, Spain; (1) orcid.org/0000-0002-0267-4020

Sandra Ruiz-Gómez - ALBA Synchrotron, Barcelona 08290, Spain

Michael Foerster - ALBA Synchrotron, Barcelona 08290, Spain

Lucía Aballe - ALBA Synchrotron, Barcelona 08290, Spain

Mar García-Hernández - Materials Science Factory, Dept. Surfaces, Coatings and Molecular Astrophysics, Institute of Material Science of Madrid (ICMM-CSIC), 28049 Madrid, Spain

José Ángel Martín-Gago - Materials Science Factory, Dept. Surfaces, Coatings and Molecular Astrophysics, Institute of Material Science of Madrid (ICMM-CSIC), 28049 Madrid, Spain; O orcid.org/0000-0003-2663-491X

Complete contact information is available at:

https://pubs.acs.org/10.1021/acsami.1c11654

\section{Author Contributions}

The manuscript was written through contributions of all authors. All authors have given approval to the final version of the manuscript.

\section{Notes}

The authors declare no competing financial interest.

\section{ACKNOWLEDGMENTS}

The authors acknowledge J.I. Martínez for fruitful discussion. This work was supported by the EU Graphene Flagship funding (Grant Graphene Core3 881603), the Spanish MICINN (MAT2017-85089-C2-1R, PID2020-115987RJ-I00 and PID2020-113142RB-C21) and the EU via the ERC-Synergy Program (Grant ERC-2013-SYG-610256 NANOCOSMOS), and the European Structural Funds via the FotoArt-CM project (P2018/NMT-4367).

\section{REFERENCES}

(1) Backes, C.; et al. Production and Processing of Graphene and Related Materials. 2D Mater. 2019, 7, No. 022001.

(2) Azpeitia, J.; Palacio, I.; Martínez, J. I.; Muñoz-Ochando, I.; Lauwaet, K.; Mompean, F. J.; Ellis, G. J.; García-Hernández, M.; Martín-Gago, J. A.; Munuera, C.; López, M. F. Oxygen Intercalation in PVD Graphene Grown on Copper Substrates: A Decoupling Approach. Appl. Surf. Sci. 2020, 529, No. 147100.

(3) Riedl, C.; Coletti, C.; Iwasaki, T.; Zakharov, A. A.; Starke, U. Quasi-Free-Standing Epitaxial Graphene on SiC Obtained by Hydrogen Intercalation. Phys. Rev. Lett. 2009, 103, 1-4.

(4) Kotsakidis, J. C.; Grubišić-Cabo, A.; Yin, Y.; Tadich, A.; MyersWard, R. L.; Dejarld, M.; Pavunny, S. P.; Currie, M.; Daniels, K. M.; Liu, C.; Edmonds, M. T.; Medhekar, N. V.; Gaskill, D. K.; Vázquez De Parga, A. L.; Fuhrer, M. S. Freestanding N-Doped Graphene via Intercalation of Calcium and Magnesium into the Buffer Layer$\mathrm{SiC}(0001)$ Interface. Chem. Mater. 2020, 32, 6464-6482.

(5) Fedorov, A. V.; Verbitskiy, N. I.; Haberer, D.; Struzzi, C.; Petaccia, L.; Usachov, D.; Vilkov, O. Y.; Vyalikh, D. V.; Fink, J.; Knupfer, M.; Büchner, B.; Grüneis, A. Observation of a Universal Donor-Dependent Vibrational Mode in Graphene. Nat. Commun. 2014, 5, No. 3257.

(6) Petrović, M.; Srut Rakić, I.; Runte, S.; Busse, C.; Sadowski, J. T.; Lazić, P.; Pletikosić, I.; Pan, Z. H.; Milun, M.; Pervan, P.; Atodiresei, N.; Brako, R.; Sokčević, D.; Valla, T.; Michely, T.; Kralj, M. The Mechanism of Caesium Intercalation of Graphene. Nat. Commun. 2013, 4, No. 2772.

(7) Pervan, P.; Lazić, P. Adsorbed or Intercalated: Na on Graphene/ $\operatorname{Ir}(111)$. Phys. Rev. Mater. 2017, 1, No. 044202.

(8) Schröder, U. A.; Petrović, M.; Gerber, T.; Martínez-Galera, A. J.; Grånäs, E.; Arman, M. A.; Herbig, C.; Schnadt, J.; Kralj, M.; Knudsen, J.; Michely, T. Core Level Shifts of Intercalated Graphene. 2D Mater. 2017, 4, No. 015013

(9) Pervan, P.; Lazić, P.; Petrović, M.; Šrut Rakić, I.; Pletikosić, I.; Kralj, M.; Milun, M.; Valla, T. Li Adsorption versus Graphene Intercalation on $\operatorname{Ir}(111)$ : From Quenching to Restoration of the Ir Surface State. Phys. Rev. B 2015, 92, No. 245415.

(10) Bao, C.; Zhang, H.; Zhang, T.; Wu, X.; Luo, L.; Zhou, S.; Li, Q.; Hou, Y.; Yao, W.; Liu, L.; Yu, P.; Li, J.; Duan, W.; Yao, H.; Wang, Y.; Zhou, S. Experimental Evidence of Chiral Symmetry Breaking in Kekulé-Ordered Graphene. Phys. Rev. Lett. 2021, 126, No. 206804.

(11) Al Hassan, M. R.; Sen, A.; Zaman, T.; Mostari, M. S. Emergence of Graphene as a Promising Anode Material for Rechargeable Batteries: A Review. Mater. Today Chem. 2019, 11, 225-243.

(12) Kühne, M.; Paolucci, F.; Popovic, J.; Ostrovsky, P. M.; Maier, J.; Smet, J. H. Ultrafast Lithium Diffusion in Bilayer Graphene. Nat. Nanotechnol. 2017, 12, 895-900.

(13) Kühne, M.; Börrnert, F.; Fecher, S.; Ghorbani-Asl, M.; Biskupek, J.; Samuelis, D.; Krasheninnikov, A. V.; Kaiser, U.; Smet, J. H. Reversible Superdense Ordering of Lithium between Two Graphene Sheets. Nature 2018, 564, 234-239.

(14) Kumar, A.; Reddy, A. L. M.; Mukherjee, A.; Dubey, M.; Zhan, X.; Singh, N.; Ci, L.; Billups, W. E.; Nagurny, J.; Mital, G.; Ajayan, P. M. Direct Synthesis of Lithium-Intercalated Graphene for Electrochemical Energy Storage Application. ACS Nano 2011, 5, 4345-4349.

(15) Teng, Y.; Zhao, H.; Zhang, Z.; Li, Z.; Xia, Q.; Zhang, Y.; Zhao, L.; Du, X.; Du, Z.; Lv, P.; Świerczek, K. MoS2 Nanosheets Vertically Grown on Graphene Sheets for Lithium-Ion Battery Anodes. ACS Nano 2016, 10, 8526-8535.

(16) Zhou, X.; Yin, Y. X.; Wan, L. J.; Guo, Y. G. Self-Assembled Nanocomposite of Silicon Nanoparticles Encapsulated in Graphene through Electrostatic Attraction for Lithium-Ion Batteries. Adv. Energy Mater. 2012, 2, 1086-1090.

(17) Su, F. Y.; He, Y. B.; Li, B.; Chen, X. C.; You, C. H.; Wei, W.; Lv, W.; Yang, Q. H.; Kang, F. Could Graphene Construct an Effective Conducting Network in a High-Power Lithium Ion Battery? Nano Energy 2012, 1, 429-439.

(18) Xie, J.; Lu, Y. C. A Retrospective on Lithium-Ion Batteries. Nat. Commun. 2020, 11, No. 2499. 
(19) $\mathrm{Xu}, \mathrm{K}$. Nonaqueous Liquid Electrolytes for Lithium-Based Rechargeable Batteries. Chem. Rev. 2004, 104, 4303-4418.

(20) Aballe, L.; Foerster, M.; Pellegrin, E.; Nicolas, J.; Ferrer, S. The ALBA Spectroscopic LEEM-PEEM Experimental Station: Layout and Performance. J. Synchrotron Radiat. 2015, 22, 745-752.

(21) Coraux, J.; T N'Diaye, A.; Engler, M.; Busse, C.; Wall, D.; Buckanie, N.; Meyer zu Heringdorf, F.-J.; van Gastel, R.; Poelsema, B.; Michely, T. Growth of Graphene on $\operatorname{Ir}(111)$. New J. Phys. 2009, 11, No. 023006.

(22) Palacio, I.; Aballe, L.; Foerster, M.; de Oteyza, D. G.; GarcíaHernández, M.; Martín-Gago, J. A. Reversible Graphene Decoupling by $\mathrm{NaCl}$ Photo-Dissociation. 2D Mater. 2019, 6, No. 025021.

(23) Palacio, I.; Otero-Irurueta, G.; Alonso, C.; Martínez, J. I.; LópezElvira, E.; Muñoz-Ochando, I.; Salavagione, H. J.; López, M. F.; GarcíaHernández, M.; Méndez, J.; Ellis, G. J.; Martín-Gago, J. A. Chemistry below Graphene: Decoupling Epitaxial Graphene from Metals by Potential-Controlled Electrochemical Oxidation. Carbon 2018, 129, 837-846.

(24) Stöhr, A.; Forti, S.; Link, S.; Zakharov, A. A.; Kern, K.; Starke, U.; Benia, H. M. Intercalation of Graphene on $\mathrm{SiC}(0001)$ via Ion Implantation. Phys. Rev. B 2016, 94, No. 085431.

(25) Silva, C. C.; Cai, J.; Jolie, W.; Dombrowski, D.; Farwick Zum Hagen, F. H.; Martínez-Galera, A. J.; Schlueter, C.; Lee, T. L.; Busse, C. Lifting Epitaxial Graphene by Intercalation of Alkali Metals. J. Phys. Chem. C 2019, 123, 13712-13719.

(26) Grånäs, E.; Knudsen, J.; Schröder, U. A.; Gerber, T.; Busse, C.; Arman, M. A.; Schulte, K.; Andersen, J. N.; Michely, T. Oxygen Intercalation under Graphene on $\operatorname{Ir}(111)$ : Energetics, Kinetics, and the Role of Graphene Edges. ACS Nano 2012, 6, 9951-9963.

(27) Virojanadara, C.; Watcharinyanon, S.; Zakharov, A. A.; Johansson, L. I. Epitaxial Graphene on $6 \mathrm{H}-\mathrm{SiC}$ and $\mathrm{Li}$ Intercalation. Phys. Rev. B 2010, 82, No. 205402.

(28) Morgan, W. E.; Van Wazer, J. R.; Stec, W. J. Inner-Orbital Photoelectron Spectroscopy of the Alkali Metal Halides, Perchlorates, Phosphates, and Pyrophosphates. J. Am. Chem. Soc. 1973, 95, 751-755.

(29) Pletikosić, I.; Kralj, M.; Pervan, P.; Brako, R.; Coraux, J.; N’Diaye, A. T.; Busse, C.; Michely, T. Dirac Cones and Minigaps for Graphene on $\operatorname{Ir}(111)$. Phys. Rev. Lett. 2009, 102, No. 056808.

(30) Vinogradov, N. A.; Simonov, K. A.; Zakharov, A. A.; Wells, J. W.; Generalov, A. V.; Vinogradov, N. A.; Mårtensson, N.; Preobrajenski, A. B. Hole Doping of Graphene Supported on Ir (111) by AlBr3. Appl. Phys. Lett. 2013, 102, No. 061601. 